\title{
Akebia: A Potential New Fruit Crop in China
}

\author{
Li Li, Xiaohong Yao, Caihong Zhong, and Xuzhong Chen \\ Wuhan Botanical Garden, Chinese Academy of Sciences, Wuhan, Hubei \\ 430074, P.R. China
}

\author{
Hongwen Huang ${ }^{1}$ \\ Wuhan Botanical Garden, Chinese Academy of Sciences, Wuhan, Hubei \\ 430074, China; South China Botanical Garden/South China Institute of \\ Botany, Chinese Academy of Sciences, Guangzhou, Guangdong 510650, \\ China
}

Additional index words. Akebia trifoliata, A. quinata, domestication, medicinal plants, Lardizabalaceae family

The Akebia Decne belongs to the Lardizabalaceae family of flowering plants, which contains approximately nine genera and 50 species (Delectis Florae Reipublicae Popularis Sinicae Agendae Academiae Sinicae Edita, 2001). The family is widespread in East Asia, whereas there are two monotypic genera occurring in Chile. The plants of the genus Akebia are perennial, deciduous vines producing large edible fruits commonly known as "wild bananas" in China. The fruit resembles a small bunch of thick bananas that crack open longitudinally when ripe in Chinese lunar August. It is therefore called "Bayuezha" (August crack) by the local people and has been prized for its delicious sweet taste for centuries in China. Species of Akebia are commonly referred to as "chocolate vine" in United States, are grown by gardeners as ornamental climbing vines, are well-known medicinal plants, and have been used in Chinese herbalism for at least 2000 years. Three species (subspecies) (A. quinata, A. trifoliata ssp. trifoliata, and A. trifoliata ssp. australis) are listed in Chinese Pharmacopoeia (Pharmacopoeia Commission of PRC, 2005). The value of the Akebia fruit and its natural compounds with antineoplastic, diuretic, and antiphlogistic properties (Jiangsu New Medical College, 1985) is of great potential for development of an alternative high-value crop. However, few studies on Akebia breeding and cultivation have been conducted and limited information is available apart from a few reports on phytochemical analyses (Gao and Wang, 2006; Kawasaki and

Received for publication 26 Aug. 2009. Accepted for publication 10 Oct. 2009.

Journal no. B090828 of Key Laboratory of Plant Resource Conservation and Sustainable Utilization, Chinese Academy of Sciences.

This research was partially supported by KIP Pilot Project of Chinese Academy of Sciences (KSCX2-YW-N-061) and CAS/SAFEA International Partnership Program for Creative Research Teams.

${ }^{1}$ To whom reprint requests should be addressed; e-mail huanghw@mail.scbg.ac.cn.
Higuchi, 1976a, 1976b). Synthesis of knowledge on these species is needed to provide insights for developing management options that enhance their conservation and contribution to fruit production.

Recent investigations suggest that Akebia is worthy of being exploited as a new high-value fruit crop in China for its health benefits and other newly found fruit properties. This article provides a broad review on the most economically important Akebia species and discusses the value of exploring these species for domestication and commercial development.

\section{Taxonomy and Geographical Distribution}

Akebia is a small genus belonging to the Lardizabalaceae and comprises four species and two subspecies endemic to China, Japan, and Korea. These include $A$. longeracemosa Matsumura, A. quinata (Houttuyn) Decaisne, A. trifoliata (Thunberg) Koidzumi, A. trifoliata ssp. longisepala H.N. Qin, A. trifoliata ssp. australis (Diels) T. Shimizu, and $A$. pentaphylla (Malino) Makino (Qin, 1997). A . trifoliata and $A$. quinata are widely distributed over East Asia, whereas A. longeracemosa is restricted to Hunan, Taiwan, and Guangdong provinces in China and A. pentaphylla is endemic to Japan (Fig. 1) (Qin, 1997).

A. quinata and A. trifoliata are the most economically important species. They are widespread in the mountain ranges of 19 provinces in China. Some of these include Gansu, Shannxi, Shanxi, and Hebei provinces in northern China; Guangdong and Guangxi provinces in southern China; Sichuan province in western China; and Shandong, Jiangsu, and Zhejiang provinces in eastern China (Fig. 1). A. quinata is also adapted to subtropical areas, from sea level to low altitudes (usually 300 to $1500 \mathrm{~m}$ ) in southeast coastal provinces. A. trifoliata has a wider geographic distribution ranging from the subtropical (lat. $24^{\circ} \mathrm{N}$ ) to temperate regions $\left(37^{\circ} \mathrm{N}\right)$, and larger vertical distribution ranging from an elevation of $\approx 300 \mathrm{~m}$ to $2500 \mathrm{~m}$. A. trifoliata is the most widely distributed species in Akebia, mainly occurring south of the Yellow River. A. trifoliata consists of two main subspecies, ssp. trifoliata and ssp. australis. The delimitation of these two subspecies largely relies on the size, shape, texture, and margins of leaflets. The A. trifoliata ssp. trifoliata plants have wider, thinner, and subpapery leaflets with irregularly sinuate margins. It grows in central China around the Yellow River valley, especially along the Qinling Mountain Range. A. trifoliata ssp. australis has narrower, thicker, and subcoriaceous leaflets with entire to subentire margins. It is mainly found in southern China, ranging from south of the Yangtze River to the central part of Taiwan Island (Qin, 1997).

Both A. quinata and A. trifoliata have a wide range of adaptability in different habitats. They are often found along forest edges, in mixed scrub forests, along roadsides, and on rocky slopes by streams and rivers. The plants thrive in well-drained, moist loamy soil and partial shade. They also show exceptionally good tolerance to heat and drought (Wang et al., 2005) and can grow well in various soil types such as sandy, clay, rocky, and lateritic soils. This wide range of geographical distribution and adaptability provides substantial genetic diversity and rich genetic resources, which can be explored for domestication and cultivar improvement.

\section{Vegetative and Floral Characteristics}

Akebia species are deciduous woody vines that may reach up 7 to $12 \mathrm{~m}$ high and are normally found in patches because of their predominantly clonal reproduction. Vines can grow upright if supported or may spread out along the ground as a groundcover. Three-year-old seedlings branch two to three times annually and the growing period is $\approx 110$ and $130 \mathrm{~d}$ per year (Xiong et al., 1996b). Shoots of Akebia can be divided into two types, creeping vines and climbing vines. One-year-old climbing vines normally produce fruit ( $\mathrm{Li}$ et al., 2006). In A. trifoliata, fruits mostly set on three to 30 buds of the 1 -year-old climbing vines (Xiong et al., 1996b). Akebia has compound leaves consisting of three to five leaflets, which are ovate to elliptic or obviate with truncate to cuneate base, entire, sinuate, or shallowly lobed margins, retuse, and an inconspicuously mucronate apex (Fig. 2). Akebia plants flower from March to May, and the flowering period lasts for 30 to $60 \mathrm{~d}$. Akebia plants are monoecious with flowers functionally unisexual (Qin, 1997). Flowers are pendulous, racemose, or rarely subumbellate inflorescence, usually produced from 1-year-old shoots (Fig. 3). These flowers, both male and female, are radially symmetrical and apetalous. Staminate flowers are found in the terminal part of raceme, which have six or seven incurved stamens, short filaments, and oblong anthers (Fig. 3A). Pistillate flowers are proximal in the raceme having three to nine carpels and each carpel secretes a large, viscous drop of fluid that receives pollen (Fig. 3B). Pistillate flowers have three to six sepals that are purplish brown to 


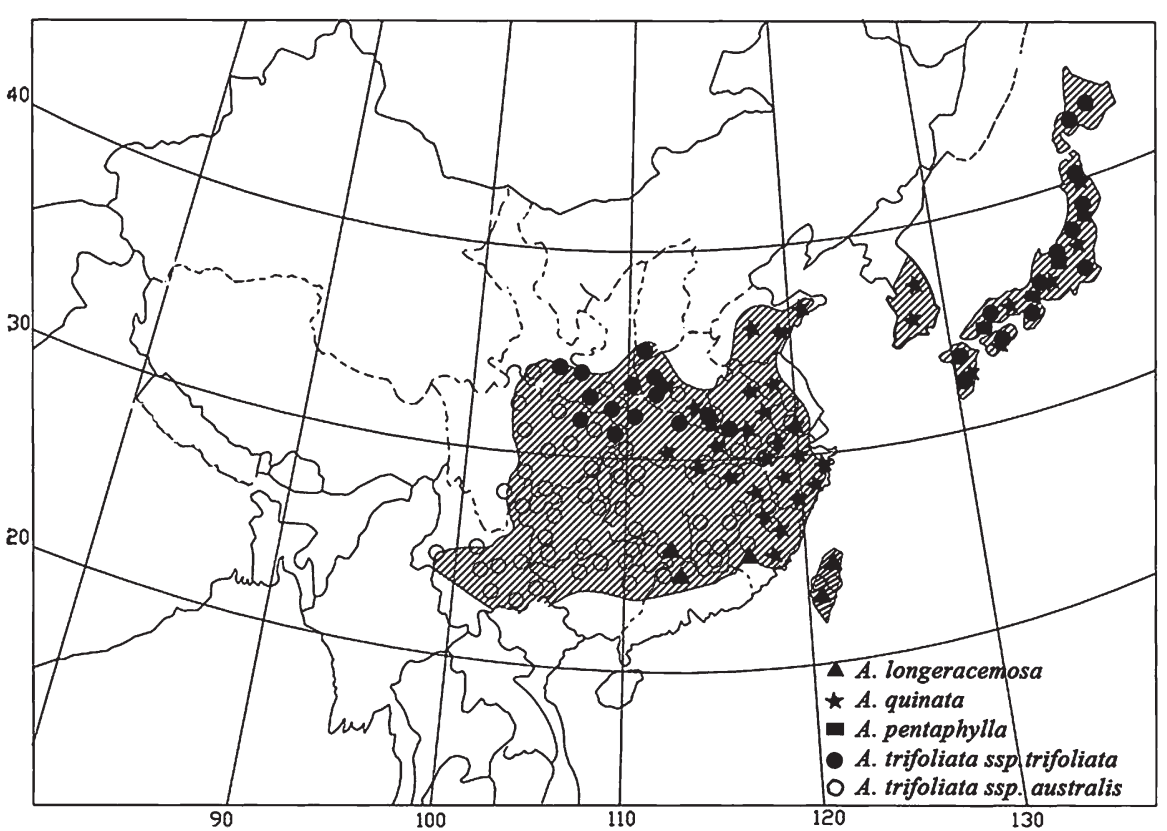

Fig. 1. Distribution of Akebia species.

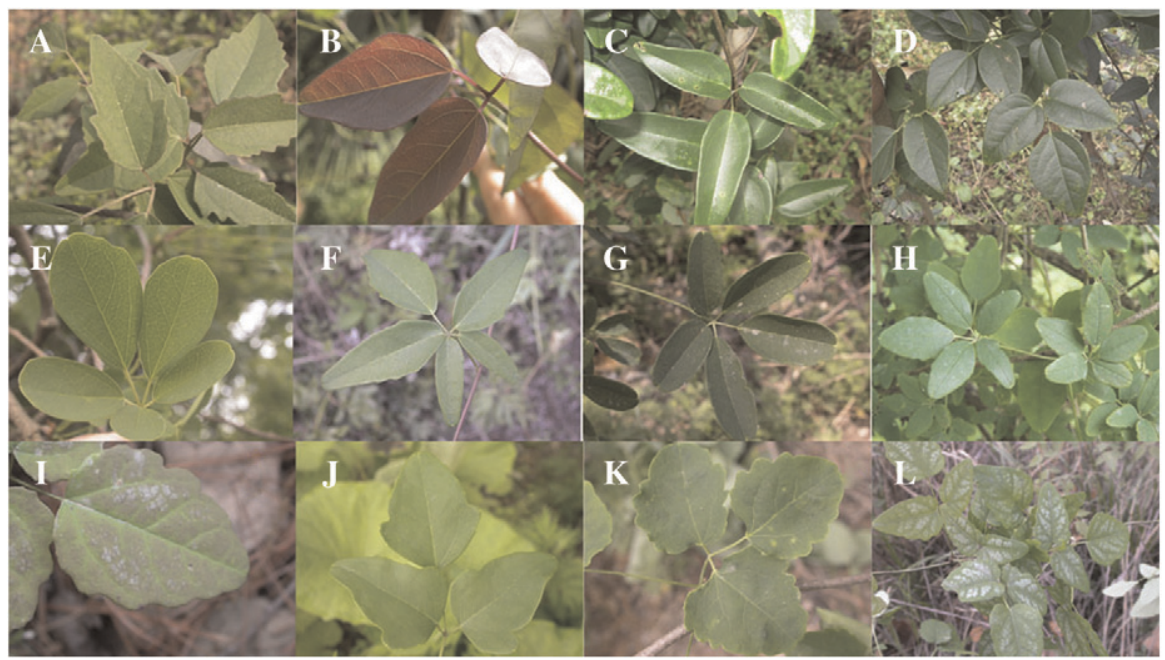

Fig. 2. Leaves of Akebia (A-D, leaflets of Akebia trifoliata ssp. australis; $\mathbf{E}-\mathbf{H}$, leaflets of Akebia quinata; I-L, leaflets of Akebia trifoliata ssp. trifoliata).

reddish purple in color (Fig. 3) (and occasionally green to white) but produce no nectaries (nectarless). The flower sizes are dimorphic with pistillate flowers being twice as large as staminate flowers (Kawagoe and Suzuki, 2002, 2003). The flowers of some Akebia species have a sweet aroma. The main difference between A. trifoliata and $A$. quinata is that $A$. trifoliata has three leaflets that are oblong-ovate to broadly ovate in shape (Figs. 2A and 2J) and longer inflorescences with more staminate flowers (Figs. 3D and 3I), whereas A. quinata has five leaflets that are oblong or obovate-oblong in shape (Figs. $2 \mathrm{E}$ and $2 \mathrm{G}$ ) and shorter inflorescences with fewer flowers (Figs. 3F and 3H). Flowers are strongly protogynous, self-incompatible, and require cross-pollination. The breeding system of Akebia remains unknown. The main pollinators observed are hoverflies and bees; however, wind pollination could not be ruled out because of characteristics such as the absence of nectaries, inflorescence shape, the dry powdery appearance of pollen grains, and immediate abscission of staminate flowers after anthesis (Kawagoe and Suzuki, 2002, 2003; Qin, 1997). Birds, animals, and even human beings are involved in seed dispersal.

\section{Fruit Characteristics}

Akebia plants have a short juvenile period and begin to flower and set fruit in the second year after regular orchard management. Fruit set in the wild is usually low; however, heavy fruit loads have been observed under orchard cultivation (Xiong et al., 1996). The yield can reach $30 \mathrm{t} \cdot \mathrm{ha}^{-1}$ in the first fruiting year and may be double this amount for mature vines (3 to 4 years after planting) under good orchard management conditions (Zhong et al., 2006). Fruit ripen over 40 to $50 \mathrm{~d}$ from late September to early November depending on latitude. The fruits are produced singly or in clusters and there is great variation in size, shape, color, flavor, and ripening time among the different Akebia species (Figs. 4, 5, and $6)$. Fruit size varies from small and round (4 $\mathrm{cm}$ in diameter) to large and oblong ( 8 to 12 $\mathrm{cm}$ long, 4 to $6 \mathrm{~cm}$ wide). The most commercially promising species, $A$. trifoliata, has the largest fruit. Significant variation in fruit weight is also observed between subspecies. Fruit weight of $A$. trifoliata ssp. trifoliata ranges from 35 to $240 \mathrm{~g}$, whereas that of ssp. australis ranges from 25 to $300 \mathrm{~g}$. Under good cultivation conditions, fruits weighing up to $546 \mathrm{~g}$ have been obtained (Zhong et al., 2006). Fruit shapes vary from nephroid to pyriform, oblong-cylindrical, and near globose. Broad variation of fruit skin color was observed both interspecifically and intraspecifically. Skin color varies from light green to purplish or brown in A. quinata (Fig. 4) and from yellow to brown, pale violet to bluish in A. trifoliata (Figs. 3 and 5). In general, the fruits with yellow or light purple skin color have a smooth texture, whereas the brown fruits have a rough texture; some fruits have small, white dots or rust spots on the surface at maturity (Figs. 3, 4, and 5). When mature, flesh color ranges from creamy to translucent white. Red flesh has also been observed in $A$. trifoliata $(\mathrm{Ou}, 2004)$. Akebia fruit has a thick rind and numerous seeds, which account for $\approx 85 \%$ of the whole fruit weight in the wild, but decreases to $50 \%$ under domestication (Zhong et al., 2006). The fruit of Akebia has a delicate and sweet flavor and a soft juicy texture, tasting like a mixture of banana, litchi, and passion fruit. However, flavor varies from some fruit displaying insipid to others having more complex flavor profiles. Akebia fruits should be harvested at optimum maturity. Once ripe, the fruits split, and flesh attracts insects and birds, resulting in contamination and yield loss. Akebia fruit is a climacteric fruit (Cao et al., 2003). The optimal harvest day is $\approx 1$ week before natural splitting and when there is a visible gray line along the ventral suture (Zhong et al., 2006). Shelf life of a vine-ripened fruit stored at room temperature is $\approx 2$ to 3 weeks because of rapid water loss and rind shrinkage but with no obvious deterioration or rot occurring to the flesh. With refrigeration, fruits harvested at optimum maturity can be stored up to 3 months while maintaining good eating quality (Wang et al., 2005). In addition, when under cold storage $7{ }^{\circ} \mathrm{C}$ with controlled oxygen $3 \%$, fruits can be stored for a longer time (Cao et al., 2003).

The fruit pulp accounts for $17 \%$ to $40 \%$ of fruit weight in the three Akebia species. The pulp contains $63.5 \%$ water and total soluble solid content ranges from $24 \%$ to $35 \%$ in mature fruit (Zhong et al., 2006). The dry fruit pulp contains $50.32 \%$ total sugar, $2.45 \%$ crude protein, $4.03 \%$ fat, $3.86 \%$ fiber, and 


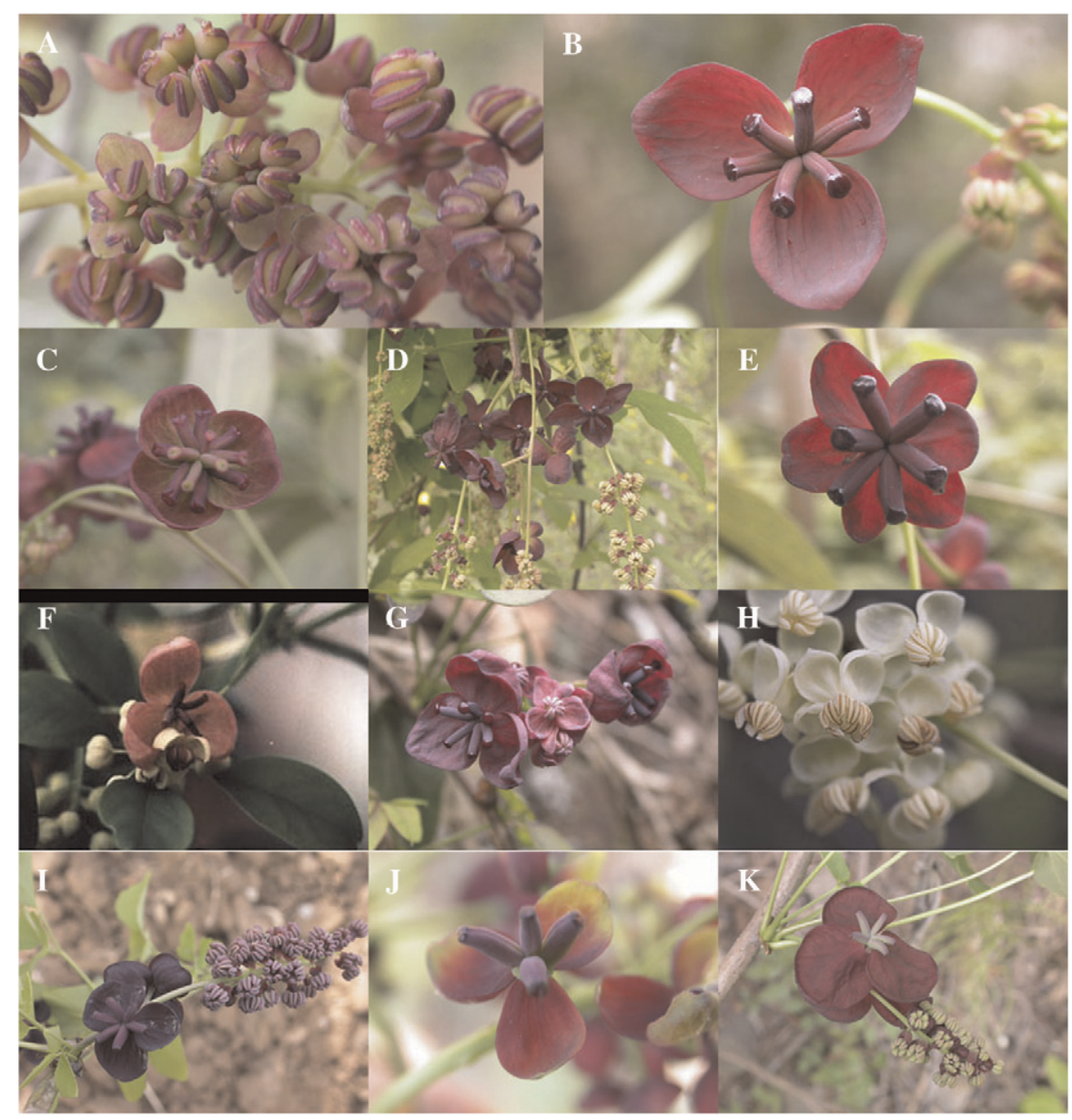

Fig. 3. Flowers of Akebia (A, male flowers of Akebia trifoliata ssp. australis; $\mathbf{B}$, female flower of Akebia trifoliata ssp. australis; $\mathbf{C}-\mathbf{E}$, inflorescences of Akebia trifoliata ssp. australis; $\mathbf{F}-\mathbf{H}$, inflorescences of Akebia quinata; $\mathbf{I}-\mathbf{K}$, inflorescences of Akebia trifoliata ssp. trifoliata).

$6.38 \%$ ash (Wang et al., 2004). Pulp sugars include fructose $(4.10 \mathrm{~g} / 100 \mathrm{~g})$, glucose $(2.78$ $\mathrm{g} / 100 \mathrm{~g})$, and sucrose $(1.57 \mathrm{~g} / 100 \mathrm{~g})$. Flesh acidity is generally low, which results in a high sugar-to-acid ratio. The principal organic acid in Akebia juice is lactic acid, with higher content $(2.12 \mathrm{~g} / 100 \mathrm{~g})$ than other acids, including citric, malic, and succinic acids (their contents add up to $0.97 \mathrm{~g} / 100 \mathrm{~g}$ ) ( $\mathrm{Li}$ and $\mathrm{Li}, 1991$ ). In comparison with other common fruits, Akebia species appear to be surprisingly rich in vitamin C (108 to $930 \mathrm{mg}$ / $100 \mathrm{~g}$ ), comparable to kiwifruit (50 to 300 $\mathrm{mg} / 100 \mathrm{~g}$ ) and roxburgh rose (Rosa roxburghii Tratt.) $(2193 \mathrm{mg} / 100 \mathrm{~g})$. Of the eight minerals detected in Akebia fruits, the concentration of potassium (K) (3.21 to $4.96 \mathrm{~g}$ / $100 \mathrm{~g}$ ) is highest followed by magnesium $(\mathrm{Mg})(1.00$ to $1.51 \mathrm{~g} / 100 \mathrm{~g})$ and calcium $(0.47$ to $0.49 \mathrm{~g} / 100 \mathrm{~g})$. In general, $\mathrm{K}, \mathrm{Mg}$, zinc, iron, and manganese contents in Akebia species are higher than other major fruits such as apple, pear, orange, and so on (Zhang et al., 2003). The fruits are also a rich source of amino acids (Liu and Qian, 2002; Wang et al., 2004). A total of 17 amino acids, including seven essential amino acids, can be found in Akebia fruit, in which the contents of glutamic acid and aspartic acid are higher than those of other amino acids (Liu and Qian,
2002). It is reported that the extracts from Akebia pulp have inhibitory functions on tyrosinase, the enzyme that makes melanin in skin pigment cells (Peng et al., 2008). The seeds of Akebia contain a large amount of fatty acids, mainly including oleic acid (47.63\%), palmitic acid $(20.14 \%)$, and linoleic acid $(27.05 \%)$ (Bai, 2007). Table 1 lists the main pomological and nutritional characteristics of Akebia fruits.

\section{Horticultural Aspects}

Akebia is an underexploited wild fruit because domestication for commercial fruit production is still in an infancy stage primarily because information on cultivation practices is limited. The greatest number of reports published emphasizes cultivation for production of herbal medicines rather than for the fruit (Xiong et al., 2006b, 2008).

Propagation. As soon as fruit ripen and split, they can be harvested for seed collection. After maceration of fruit in water and floating off the pulp, seeds are traditionally extracted and then dried in the shade (Xiong et al., 2005). Under optimal storage conditions, seeds can remain viable for 2 to 3 years. Seeds require stratification to overcome dormancy and for embryo maturation. Refrigerated stor- age $\left(5^{\circ} \mathrm{C}\right)$ for $14 \mathrm{~d}$ is recommended to overcome embryo dormancy (Xiong et al., 2006c).

Stratified seeds can be planted either in a prepared seed bed or in containers. It is reported that the seedcoat may hamper germination of Akebia to a certain degree. A traditional practice to enhance germination is to soak and rub the seedcoat with either a $10 \%$ tea solution or with plant ashes (Xiong et al., 2006c). For large-scale container production, it is recommended to pregerminate seeds in either petri dishes or moist sand germination plates with appropriate temperature and moisture management, in which case seed germination is normally above $80 \%$ (Xiong et al., 2005, 2006c). Pregerminated seeds can then be sown directly into seed beds. The seeds should be sown to a $2-$ to 3 -cm depth in a moist, well-drained soil or other growth medium (Xiong et al., 2006a). Three months after sowing when seedlings grow $\approx 30 \mathrm{~cm}$ tall, they are ready for transplanting in the field. Although trees can be planted in the fall, better transplant success occurs with spring planting. Akebia vines prefer moist, fertile, well-drained, and slightly acid soils (i.e., $\mathrm{pH} 4.89$ to 6.62 ), but they can tolerate a variety of soil types (Guo et al., 2005).

Akebia species can be asexually propagated by root cutting, hard and softwood cutting, grafting, and layering. Propagation by cuttings is successful during either winter or summer, depending on what type of stem cutting is taken. Cuttings should be taken from 3- to 4-year-old twigs (Cao et al., 2008). We have observed best success with twigs greater than $0.5 \mathrm{~cm}$ in diameter having welldeveloped buds. The rooting percentage can be markedly improved by treatment with auxin (e.g., ABT-2 rooting powder, invented by the Chinese Academy of Forestry) (Zhou et al., 2002). For the propagation of cuttings, shade of $\approx 60 \%$ of full sunlight is required (Cao et al., 2008). Self-layering or transplanting trees from the wild can also be highly successful.

Orchard management. Akebia vines grow vigorously and require a trellis system to support fruiting canes in the second year ( $\mathrm{Li}$ et al., 2006). There are three training systems for Akebia: "overhead pergola," "hedge fence trellis," and "T"-bar trellis." In orchard cultivation, the " $\mathrm{T}$ "-bar trellis system is recommended. Vines can be planted 1.5 to $2.0 \mathrm{~m}$ apart in $3.0-$ to $3.5-\mathrm{m}$ wide rows and trained with one trunk and two strong lateral leaders growing in opposite directions along a center wire similar to grapes. Dormant winter pruning is needed to achieve and maintain good vine form. When pruning, vigorous vegetative shoots are removed or cut back to leave seven to 15 buds, which may serve as replacement for fruiting canes. For vigorous fruiting shoots, select currentseason canes and cut to a three- to four-bud stub. The renewal spurs will produce the fruiting arms to be used the next season. Akebia vines have strong regeneration ability (Li et al., 2006). When production capacity decreases, the whole plant can be cut at its base while leaving one strong sprout to be the future vine. To reduce vine vigor and 


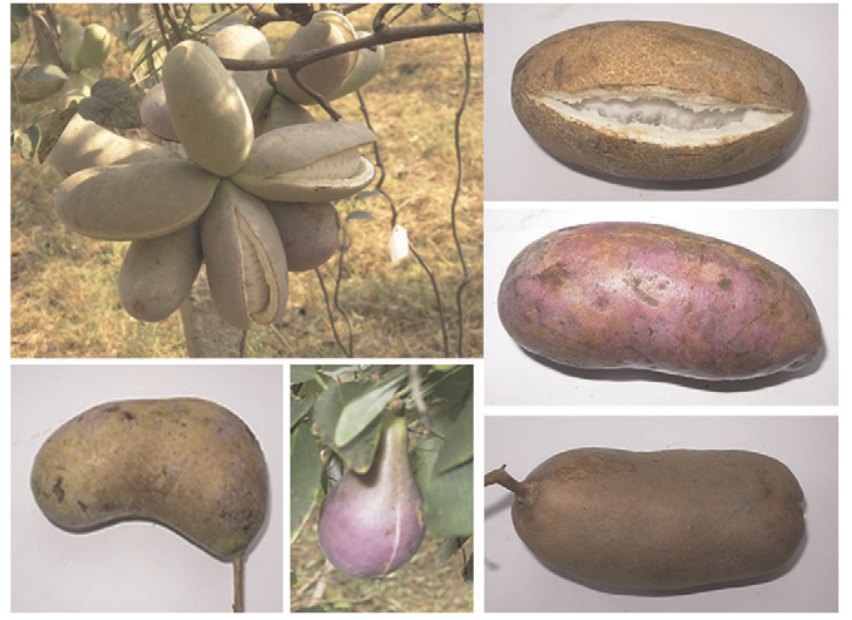

Fig. 4. Mature fruits of Akebia trifoliata ssp. australis.

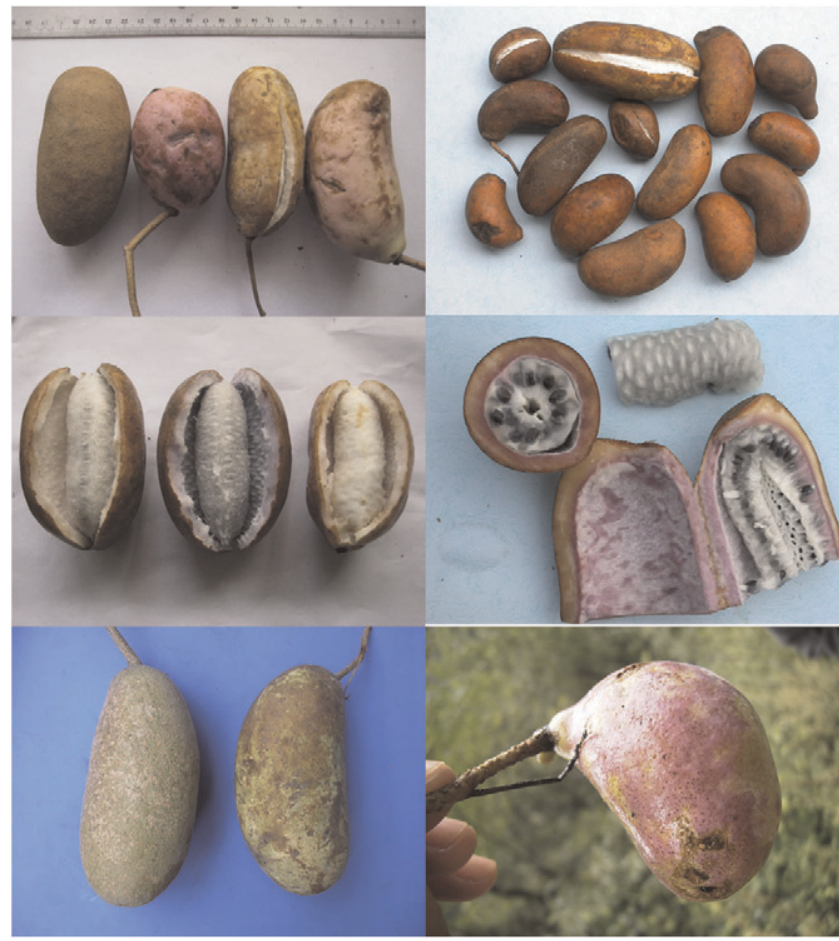

Fig. 5. Fruits of Akebia trifoliata ssp. trifoliata.

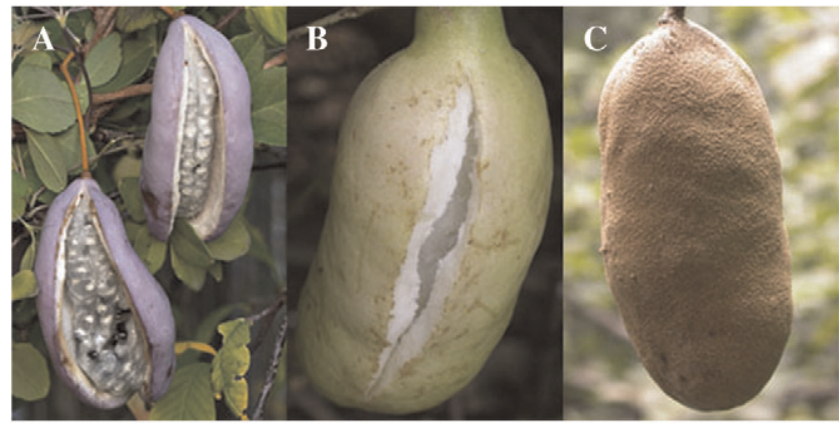

Fig. 6. Fruits of Akebia quinata.

promote fruit development, summer pruning at regular intervals during the growing season is necessary. This includes shoot tip removal, shoot thinning, and fruit thinning.
As long as natural rainfall is sufficient, irrigation is usually not required, but it can enhance growth during establishment and early vine life, especially during the dry season (Xiong et al., 2006b). The soil should be kept moist but not saturated. It is essential that the soil is well-drained for optimal production.

Information on fertilization requirements of Akebia is limited. In experimental cultivation of $A$. trifoliata, annual fertilizer supply of 5.94 to $6.4 \mathrm{~kg}\left(100 \mathrm{~m}^{2}\right)^{-1}(3 \mathrm{~N}-2 \mathrm{P}-4 \mathrm{~K})$ once in February, March, and May was found to improve growth and fruit production (Xiong et al., 2007). According to our observation on A. trifoliata ssp. australis, the fruit growth curve has two peaks: 1 month after flowering (April) and 1 month before fruit ripening (August) in Wuhan, Hubei Province. Application of a quick-release fertilizer in April and August enhances fruit growth. After harvest and before leaf abscission, fall applications of manure or slow-release fertilizers is advised.

All Akebia plants are self-incompatible. To enhance fruit set, hand pollination is necessary. Few diseases have been recorded on Akebia. In Japan, anthracnose caused by Colletotrichum acutatum was found on $A$. trifoliata (Kobayashi et al., 2004). When seriously infected, the leaves often wilt and fall off. Powdery mildew has also been observed on fruits during our collection, giving fruit a rough skin texture, but it has no influence on fruit flavor.

\section{Domestication and Research Efforts}

In China, Akebia fruits collected in the wild have been used for centuries for medicinal purposes. They are widely used to treat urinary tract infections, scanty lactation, and rheumatoid arthritis (Commission of Herbal Medicine in China, 1999; Xiao and Lian, 1999). They also have been shown to have stimulatory effects on blood circulation and to have anticancer properties (Dharmananda, 1997; Hsu, 1990). Unfortunately, high demand for Akebia has caused a serious reduction in the number of fruits available to harvest in the wild. As early as the 1960s, dramatic declines in wild populations have occurred because of overharvesting and deforestation (Lou and Qin, 1996). After 1977, Akebia species recorded in Chinese Pharmacopoeia as "Mutong" was replaced by "GuanMutong" (Aristolochia species), which has led to serious renal failure in recent years as a result of its high content of aristolochic acid. Therefore, the medicinal source of "Mutong" attracted considerable attention from the Chinese government. Researchers indicate that these toxic ingredients were not found in Akebia species (Zhou et al., 2006). Akebia species were therefore defined as the only authentic medicinal plant of "Mutong" and relisted in Chinese Pharmacopoeia in 2005 (Pharmacopoeia Commission of PRC, 2005). At the same time, a program, "research on cultivation and propagation of $A$. trifoliata," was initiated to improve the endangered status of Akebia. This was supported by a grant from the National Key Technologies R \& D Program of China 
Table 1. Main pomological and nutritional characteristics of Akebia fruits.

\begin{tabular}{|c|c|c|c|c|c|c|c|c|c|}
\hline Species & Fruit $\mathrm{wt}^{\mathrm{z}}(\mathrm{g})$ & $\begin{array}{l}\text { Fruit diam }{ }^{z} \\
\qquad(\mathrm{~mm})\end{array}$ & $\begin{array}{l}\text { Fruit length }{ }^{z} \\
\qquad(\mathrm{~mm})\end{array}$ & $\begin{array}{c}\text { Skin } \\
\text { thickness }{ }^{\mathrm{z}}(\mathrm{mm})\end{array}$ & $\begin{array}{c}\text { Seed } \\
\text { number }^{z}\end{array}$ & $\begin{array}{c}\text { Edible flesh }{ }^{z} \\
(\%)\end{array}$ & Skin color ${ }^{2}$ & Skin texture ${ }^{z}$ & Fruit shape ${ }^{z}$ \\
\hline A. quinata & $30.2-99.4$ & $33.3-45.5$ & $40.8-104.2$ & $5.0-6.9$ & $58-115$ & $16.5-28.2$ & $\begin{array}{l}\text { Light green, } \\
\text { purple, and } \\
\text { brown }\end{array}$ & Smooth, rough & Oblong \\
\hline $\begin{array}{l}\text { A. trifoliata ssp. } \\
\text { trifoliata }\end{array}$ & $34.5-238.7$ & $37.0-61.5$ & $48.5-119.3$ & $5.4-11.5$ & $50-258$ & $17.5-28.4$ & $\begin{array}{l}\text { Brown, yellow, } \\
\text { and red purplish }\end{array}$ & Smooth, rough & $\begin{array}{l}\text { Nephroid, oblong, } \\
\text { and near globose }\end{array}$ \\
\hline $\begin{array}{l}\text { A. trifoliata ssp. } \\
\text { australis }\end{array}$ & $23.5-304.4$ & $26.4-63.3$ & $48.2-130.5$ & $4.3-9.8$ & $50-350$ & $18.2-41.3$ & $\begin{array}{l}\text { Brown, maroon, } \\
\text { light green with } \\
\text { purplish, and } \\
\text { pale violet }\end{array}$ & $\begin{array}{l}\text { Smooth, rough, } \\
\text { sometimes } \\
\text { with white dots } \\
\text { on surface }\end{array}$ & $\begin{array}{l}\text { Nephroid, oblong, } \\
\text { and pyriform }\end{array}$ \\
\hline
\end{tabular}

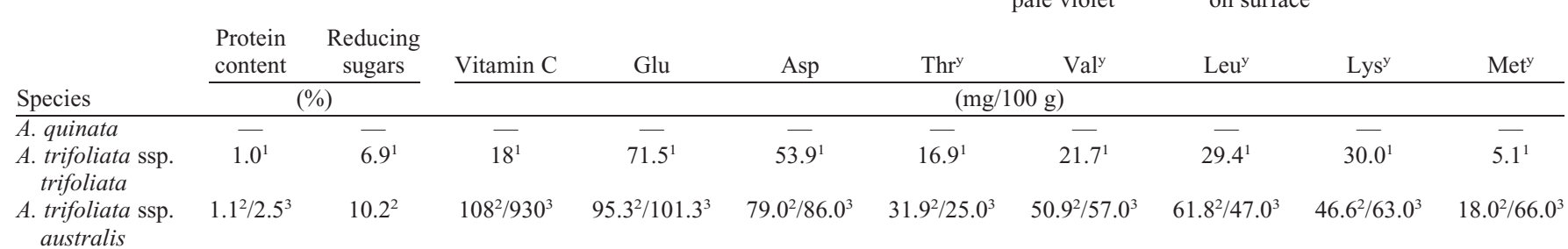

\begin{tabular}{|c|c|c|c|c|c|c|c|c|c|c|}
\hline \multirow[b]{2}{*}{ Species } & $\mathrm{Ile}^{\mathrm{y}}$ & $\mathrm{Phe}^{\mathrm{y}}$ & Potassium & Magnesium & Calcium & Sodium & Zinc & Iron & Manganese & Copper \\
\hline & \multicolumn{10}{|c|}{$(\mathrm{mg} / 100 \mathrm{~g})$} \\
\hline A. quinata & - & - & $321.9^{4}$ & $100.7^{4}$ & $49.7^{4}$ & $0.4^{4}$ & $2.1^{4}$ & $3.2^{4}$ & $1.6^{4}$ & $0.7^{4}$ \\
\hline $\begin{array}{l}\text { A. trifoliata ssp. } \\
\text { trifoliata }\end{array}$ & $16.1^{1}$ & $18.4^{1}$ & $340.4^{4}$ & $102.5^{4}$ & $48.4^{4}$ & $0.2^{4}$ & $1.9^{4}$ & $1.0^{4}$ & $1.7^{4}$ & $0.9^{4}$ \\
\hline $\begin{array}{l}\text { A. trifoliata ssp. } \\
\text { australis }\end{array}$ & $48.6^{2} / 54.0^{3}$ & $40.5^{2} / 18.0^{3}$ & $496.2^{4}$ & $151.1^{4}$ & $47.2^{4}$ & $0.8^{4}$ & $2.4^{4}$ & $0.8^{4}$ & $2.1^{4}$ & $0.6^{4}$ \\
\hline
\end{tabular}

${ }^{\mathrm{z}}$ Data source: Li, unpublished data; ${ }^{1} \mathrm{Li}$ and Li, 1991; ${ }^{2} \mathrm{Liu}$ and Qian, 2002; ${ }^{3}$ Wang et al., $2004 ;{ }^{4} \mathrm{Zhang}$ et al., 2003.

${ }^{\mathrm{y}}$ Essential amino acids.

$-=$ no information available.

in the beginning of this century (Huang et al., 2005). In recent years, the Chinese government successively established several production bases of Akebia medicinal materials in Hunan, Hubei, Shaanxi, and Henan provinces. However, wild plants have so far been the main source of medicinal plant material.

Since the 1950s, the collection, preservation, and use of fruit germplasm resources have been carried out on a wide scale all over the country. Many botanists and horticulturists realized that Akebia was a valuable wild fruit worthy of exploration and use. In the last 10 years, Akebia fruit from the wild has received increased attention because of its nutritional value and potential contribution to a healthy diet (Wang et al., 2005). The fruit are very nutritious, higher in vitamins, minerals, sugars, and crude proteins than apple, strawberry, and pear (Liu and Qian, 2002). The pulp is deliciously sweet when eaten fresh, flavored with vanilla, or mixed with ice cream, yogurt, or pudding. It also can be served as tropical-tasting clear jelly or flavorful drink. Recent studies suggest that Akebia fruit has outstanding cleansing, whitening, and antiaging functions so that it can be used as an ingredient in skin care cosmetics (Wang et al., 2005). Furthermore, the rich content of unsaturated oils in Akebia seeds gives it great potential for reducing the risk of heart disease. Harvesting fruits from the wild provides important food supplements and cash income for local people in rural communities. In mountain ranges, many people love to eat Akebia fruits, collecting and selling them in local markets. In 2009, fruits may sell for 1-3 U.S. Dollar/kg at the local markets. Nevertheless, there are no commercial plant- ings in China except for some amateur horticulturists despite its well-recognized potential and high prices in local markets. The current overexploitation of natural sources of Akebia is leading to the loss of fruit sources and also to the depletion and erosion of the natural gene pool of these species. Therefore, the domestication and cultivation of Akebia is necessary to provide a sustainable source for a new fruit and herbal medicine industry.

Fortunately, during the past 10 years, some local governments and research institutes have conducted advanced research on the domestication and commercialization of these fruit vines. Vines with superior phenotypes of $A$. trifoliata ssp. trifoliata have been selected from the wild by rural dwellers and fruit experts from 1997 in Huxian of Shaanxi Province. Selection was based on jointly determined criteria (fruit size, sweetness, fruit load, fruit appearance, time of ripening, and resistability) and two excellent individuals were chosen for clonal propagation experiments (Zhang, 2007). In 1999, Hunan Horticultural Research Institute initiated a wide-ranging research project on Akebia, emphasizing germplasm collection, breeding, cultivation, storage, and processing, with promising results (Wang et al., 2005). Numbered clones were propagated and are undergoing replicated trials to identify the best materials. The Wuhan Botanical Garden (WBG, The Chinese Academy of Sciences) has also had a comprehensive research program since 2005 directed toward developing Akebia as a new commercial fruit crop in China. Ongoing research at WBG includes: 1) making an inventory of natural resources, investigating geographic distribution, and selecting for superior clonal genotypes based on horticultural traits (i.e., fruit size, color, taste, and flesh-to- fruit ratio) for further domestication and breeding; 2) developing appropriate cultural recommendation for orchard production; 3) investigating the ecophysiology and phenology of species of different origin; 4) selecting, developing, and propagating superior, commercially desirable cultivars; 5) determining heritabilities for commercially important traits; 6) establishing postharvest handling techniques; and 7) characterizing the morphological and molecular variation in a diverse germplasm collection. Progress has been made in advanced selection of superior genotypes of Akebia for orchard production.

Domestication and breeding of Akebia has also taken place in Japan. Farmers have made superior selections of Akebia from the wild and cultivated them. Currently, several selections with desirable traits have been developed. In 1998, an exploration for Akebia in Gumma and Yamagata prefectures was conducted and 63 samples were collected, including clones that had tolerance to powdery mildew (Nobuko et al., 1999). In the past, Akebia species in Japan have always been cultivated as an ornamental plant in edible landscapes or as "bonsai" for home decoration. Where they were introduced to the United States, France, and United Kingdom as ornamentals, they are still sold for that use. At present, several ornamental varieties were selected because of their showy and variable flowers. However, Akebia flowers are so small and inconspicuous that they are often hidden by thick foliage, which may limit the development of Akebia as an ornamental plant. Until 
now, the potential of these varieties as ornamentals has remained virtually untapped in China.

\section{Conclusion}

Commercially, Akebia species appear to have several selling points such as: 1) the eye-appealing quality of fruit shape and color; 2) nutritional and cosmetic value of the fruit; and 3) medicinal properties of the fruit. It is well suited as a fresh or processed fruit or as a component in residential "edible" landscapes. Agronomically, these species are generally easy to propagate and cultivate. They also have strong adaptation to diverse climatic and soil conditions. In general, they produce fruits quickly and have few disease and pests. Perhaps they may be a suitable candidate for organic or low-input, sustainable production systems. Akebia has tremendous potential as a new fruit crop for further domestication and commercialization in China. For domestication of new clonal selections to be successful, the crop must possess favorable horticultural traits such as high yield, large edible fruits, good taste, long-yielding season, and high nutrient content. Fortunately, the genus Akebia offers breeders a wealth of genetic variation and product opportunities. Within the two main commercial species, A. quinata and A. trifoliata, considerable genetic variation has been found in several important fruit and vine characters, including fruit size, shape, skin color, thickness of peel, pulp:fruit ratio as well as taste and nutrients. The further characterization of these differences is important in the domestication of these species and their orientation for different uses and to different markets. Consumers are reluctant to eat fruit with a thick peel and numerous seeds, so the flesh-to-seed ratio might be a key selection criterion. However, these undesirable horticultural traits for fresh fruit production are acceptable when fruit are used for pharmaceutical purposes. At present, the absence of selected cultivars limits the possibility for large-scale product development. Once improved varieties are obtained, the commercialization of the fruits could be easily planned and promoted.

More detailed knowledge of Akebia is required to guide its greater use and production. Currently, there have been only sporadic reports on Akebia resources (Ou, 2004; Zhang, 2001), fruit quality ( $\mathrm{Li}$ and $\mathrm{Li}$, 1991; Liu and Qian, 2002; Wang et al., 2004), and biological characteristics ( $\mathrm{Li}$ et al., 2006; Xiong et al., 1996). There exists a lack of knowledge on the extent and distribution of genetic variation within and between plant populations. This is essential for determining appropriate genetic management strategies both for use and conservation purposes. The knowledge about genetics, breeding, and cultivation is still insufficient and merits further research. The necessity of a nationwide cooperative program for the conservation of these genetic resources, exploitation of new uses, enterprise and product development, and market research of these wild fruit tree species should be emphasized.

\section{Literature Cited}

Bai, C. 2007. Fatty acids analysis in Decaisnea insignis and Akebia trifoliata seed oil by GCMS. Acta Botanica Boreali-Occidentalia Sinica 27:1035-1038.

Cao, L., L. Huang, A. Shao, and L. Huang. 2008. Study on the factors of influencing for cottage seedling of Akebia trifoliata. Research and Practice of Chinese Medicines 22:3-6.

Cao, Y., D. Xiong, J. Zhu, H. Yu, and G. Li. 2003. Study on the respiration physiology of Akebia trifoliata fruit and the suitable storage conditions. Journal of Fruit Science 20:512514.

Commission of Herbal Medicine in China. 1999. Omnibus of herbal medicine in China. Vol. 3. Shanghai Technology Press, Shanghai, China. p. 330-331.

Delectis Florae Reipublicae Popularis Sinicae Agendae Academiae Sinicae Edita. 2001. Flora Reipublicae Popularis Sinicae. Tomus 29. Science Press, Beijing, China. p. 1-11.

Dharmananda, S. 1997. The treatment of gastrointestinal cancers with Chinese medicine. 7 July 2009. <http://www.itmonline.org/arts/gicancer. $\mathrm{htm}>$.

Gao, H. and Z. Wang. 2006. Triterpenoid saponins and phenylethanoid glycosides from stem of Akebia trifoliata var. australis. Phytochemistry 67:2697-2705.

Guo, C., D. Xiong, J. Wang, W. Wang, Z. Xi, Z. Li, and J. Yu. 2005. Preliminary study on soil applicability analyse of introducing variety planting with the Akebia quinata. Journal of Hunan Agriculture University 31:364-366 (Natural Science)

Hsu, H. 1990. Treating cancer with Chinese herbs. Oriental Healing Arts Institute, Long Beach, CA.

Huang, L., L. Guo, G. Cui, P. Xiao, and Y. Wang. 2005. Study on the basic theory of sustainable use of Chinese Medicine Resource. Research \& Information of Traditional Chinese Medicine $7: 4-6$.

Jiangsu New Medical College. 1977. Dictionary of Chinese herbal medicine. Shanghai Science and Technology Press, Shanghai, China. p. 357-359.

Kawagoe, T. and N. Suzuki. 2002. Floral sexual dimorphism and flower choice by pollinators in a nectarless monoecious vine Akebia quinata (Lardizabalaceae). Ecol. Res. 17:295303.

Kawagoe, T. and N. Suzuki. 2003. Flower-size dimorphism avoids geitonogamous pollination in a nectarless monoecious plant Akebia quinata. Intl. J. Plant Sci. 164:893-897.

Kawasaki, T. and R. Higuchi. 1976a. Pericarp saponins of Akebia quinata decene I. Glycosides of hederagenin and oleanolic acid. Chem. Pharm. Bull. (Tokyo) 24:1021-1032.

Kawasaki, T. and R. Higuchi. 1976b. Pericarp saponins of Akebia quinata Decne II. Arjunolic and norarjunolic acids, and their glycosides. Chem. Pharm. Bull. (Tokyo) 24:13141323.

Kobayashi, Y., T. Tsukamoto, N. Miyai, and Y. Nakanishi. 2004. Anthracnose of three-leaf akebia (Akebia trifoliata Koidzumi) caused by Colletotrichum acutatum. J. Gen. Plant Pathol. 70:295-296.

Li, J. and J. Li. 1991. Studies on biological characteristics and nutrients of fruit in threeleaf akebia. Guihaia 11:189-192.
Li, Z., H. Wan, and X. Gong. 2006. Preliminary observation on the stem growth characteristic of Akebia trifoliata. Journal of Chinese Medicinal Materials 29:214-215.

Liu, L. and Z. Qian. 2002. Determination of nutritional components in fruit of Akebia trifoliata Koidz. Journal of Southeast Guizhou National Teacher's College 20:39-41.

Lou, Z. and B. Qin. 1996. Species systematization and quality evaluation of commonly used Chinese traditional drugs. Peking University Medical Press, Beijing, China. p. 87-90.

Nobuko, M., S. Yoshihiko, and S. Moriyuki. 1999. Exploration for Akebia genetic resources in Gunma and Yamagata prefectures in Japan. Annual Report Exploration and Introduction of Genetic Resources 15:15-21.

$\mathrm{Ou}, \mathrm{M}$. 2004. Several major wild fruit resources of Lardizabalaceae and their utilization appraisal. Xi Nan Nong Ye Xue Bao 17:368-370.

Peng, D., C. Zhong, H. Zhou, B. Zeng, and Z. Wang. 2008. The inhibitory effects in vitro of ethanol extracts from the fruit of Akebia trifoliata on the tyrosinase activity. Journal of Wuhan Botanical Research 26:183185.

Pharmacopoeia Commission of PRC. 2005. Pharmacopoeia of the People's Republic of China. Vol. 1. Chemical Industry Press, Beijing, China. p. 43, 208.

Qin, H. 1997. A taxonomic revision of the Lardizabalaceae. Cathaya 8-9:52-76.

Wang, D., F. Li, J. Yuan, and H. Zhong. 2004. Study and application of nutritional components of wild plant Var australis (Diels) Rehd. Amino Acids \& Biotic Resources 26:16-17.

Wang, Z., C. Zhong, F. Bu, D. Peng, J. Peng, and F. Yuan. 2005. Akebia - a valuable wild fruit under domestication. Agricultural Science \& Technology Newsletter 6:12-18.

Xiao, P. and W. Lian. 1999. The illustrated medicinal plants of China. China Agriculture Press, Beijing, China. p. 105.

Xiong, D., Y. Cao, and J. Zhu. 1996a. Studies on fruit setting and fruit growth habit of Akebia trifoliata under artificial cultivation. Journal of Wuhan Botanical Research 14:89-93.

Xiong, D.S., Y. Cao, Z. Mon, and J. Zhu. 1996b. Studies on biological characteristics of Akebia trifoliata. Journal of Southwest Agricultural University 18:85-90.

Xiong, D., C. Guo, and Z. Qin. 2006a. Studies on techniques of the intensive cultivation land sector and the entire way of Akebia trifoliata. Journal of Hunan University of Arts and Science 18:42-44 (Natural Science).

Xiong, D., J. Wang, Z. Li, and R. Zhao. 2006b. Study on normalized operational regulations for production of Akebia trifoliata. Modern Chinese Medicine 8:37-40.

Xiong, D., C. Guo, and B. Xie. 2005. Seed quality characteristics of Akebia trifoliata. Chin. Tradit. Herbal Drugs 36:1710-1713.

Xiong, D., H. Hu, L. Guo, Z. Jiang, and Z. Lu. 2008. Comparative study on the cultivated density and artificial prune skill for three Akebia. Journal of Hunan University of Arts and Science 20:60-63 (Natural Science)

Xiong, D., J. Wang, Z. Xi, and G. Lin. 2006c. Study on the seed dormancy and germination technology of Akebia trifoliata. Journal of Hunan University of Arts and Science 18:46-49 (Natural Science)

Xiong, D., Y. Xiong, Z. Xi, and J. Mei. 2007. Highyield cultivation technique of Akebia tifoliata (Thunb) Koidz. Journal of Hunan Agriculture University 33:156-159 (Natural Science). 
Zhang, J. 2007. Study on introduction and domestication of wild plant Akebia trifoliata which can be both used as herbal and fruit plant. Master's thesis, Northwest A \& F University, China. p. 1-40.

Zhang, X. 2001. Investigation of Akebia resources in Xiangxi of Hunan Province. Journal of Jishou University 22:39-41 (Natural Science).
Zhang, X., Z. Yang, S. Liu, and G. Chen. 2003. Determination of trace elements of fruits of Akebia Decne in western Hunan. Chinese Wild Plant Resources 22:44-46.

Zhong, C., F. Bu, Z. Wang, and D. Peng. 2006. Fruit development and biological characteristics of seedling progenies of Akebia trifoliata. Hunan Agricultural Sciences: $27-$ 29.
Zhou, H., M. Chen, and Q. Wu. 2002. Study on raising seedlings by cutting for new fruit Akebia trifoliata. Seed 6:108-109.

Zhou, X., C. Zheng, J. Sun, and T. You. 2006. Analysis of nephroloxic and carcinogenic aristolochic acids in Aristolochia plants by capillary electrophoresis with electrochemical detection at a carbon fiber microdisk electrode. J. Chromatography 1109:152-159. 